\title{
The Incorporation of Mahara E-Portfolio Platform into English Speaking Course
}

\author{
Wencao Sun \\ School of Foreign Languages, Wuhan Polytechnic University, Wuhan, China \\ 420300466@qq.com
}

\begin{abstract}
Keywords: Mahara; E-Portfolios; Speaking course; Personalized learning
\end{abstract}
\begin{abstract}
Speaking course is an important part of college English teaching in China, but traditional teaching model cannot meet the new social requirement. Government and universities are developing new models of English teaching in a networked environment. Mahara, an open-source learning platform with e-Portfolio, web blog, resume and learning communities, is designed to provide users with lifelong learning, reflective learning and personalized learning. The paper analyses the benefits and challenges of incorporation of e-Portfolios into speaking course.
\end{abstract}

\section{Introduction}

In the last two decades, education technology has been developing at a dramatic rate in many countries since traditional educational model cannot meet the new social requirement. With the wide use of Internet, learners are exposed to the wider world. This exposure permits learners to discover new information and combine a variety of media in order to reach in-depth and broader understanding of their literacy and the world (Cole, Ryan, Kick, \& Mathies, 2000) [1]. Currently information technology has revolutionized education models and concepts and has become an integral part of higher education. As early as 2003, Yaoxue Zhang, the Secretary of Higher Education Department in China, pointed out that the reform of college English course would be the first course to make a significant breakthrough in shifting traditional education model with advanced technologies. In order to promote the reform of college English, "College English Curriculum Requirements" issued by the Ministry of Education in China in 2007, clearly states: Colleges and universities should take full advantage of modern information technology, and apply computer-based teaching model. The new model should be based on modern information technology, particularly network technology, to support teaching and learning without restrictions of time and space to some extent. Personalized learning and autonomous learning will be the trend of the reform. Also, college English curriculum should be designed to emphasize students' listening and speaking abilities by developing network-based courses with good language learning environment. In fact, students' speaking ability has long been criticized by the society in China. With the advance of college English reform, the study of speaking course has drawn the attention of scholars and educators. Teachers all over the world have been exploring to incorporate technology into teaching, creating new teaching models such as flipped classroom, blended learning and collaborative online teaching, etc. Students are more engaged in learning when technology is involved, and technology can aid in learning being more tailored to specific learners' needs (Nelson, Palonsky, \& McCarthy, 2010)[2].E-portfolio, an excellent digital tool, has been used at universities in the United States, Europe, Australia, New Zealand and in parts of Asia. English teachers in China are trying to use e-portfolio to facilitate student learning and record progress.

\section{Background}

Definitions of E-Portfolios. In the 1980s, portfolio was used as a tool for sharing work in the United States. It was in the form of a folder to collect students' work and reflection report over a period of time. E-portfolio is an electronic form of portfolio. Butler (2006) indicated that an 
e-portfolio is used for students while studying, for teachers and institutions while assessing their work, and for graduates while searching for a job. Hence, using e-portfolios is a lifelong learning that accompanies the individual for many years[3].Barrett (2000) and Abrami and Barrett (2005) describe the e-portfolios as "a digital container (that is) capable of storing visual and auditory content including text, images, video, and sound" [4][5].From the above definitions, we can grasp the purpose of e-portfolios is to let students collect works and document learning outcomes.

Problems of College English Speaking Course. With the process of globalization, good English communication ability has become increasingly important. However, college students' English speaking capabilities are not satisfying in the view of teachers, employers and even students themselves. Given the limitation of class hours, speaking course at many universities in China cannot achieve desired effect. Specifically, the following are challenges and difficulties of college speaking course.

Insufficient Motivation. Students don't have strong motivation to improve speaking skills. Although many students are aware of the importance of speaking ability, most students are more concerned with passing the course than with learning and therefore did only minimum work required to get a reasonable grades. In high school, speaking ability is not emphasized because speaking is not tested in college entrance examination, which is the most important test in China. At present, many college students' achievements are based on scores from paper and pencil tests, which encourage great test takers, but fail to produce creative people with critical thinking skill. Speaking, however, cannot be evaluated through paper and pencil tests and is regarded as the most difficult skill to be assessed. Consequently, many non-English major students are unmotivated because they see speaking class as barely relevant and even a burden.

Lack of Practice. Owing to lack of authentic English-speaking environment, students don't have many opportunities to practice speaking skill with native speakers in real life. They have poor and sometimes false understanding about their speaking ability. Some students are very reluctant to speak in English because they think their oral English is bad. Some others dare not to open their mouth because of poor pronunciation, lack of vocabulary and confidence. In class, speaking in front of teachers and classmates is intimidating for some students because they are afraid of "losing face" and being laughed at by classmates. Due to anxiety, students tend to sit by, remain silent and uninvolved and therefore lose the chance to improve speaking skill.

Large Class. Speaking classes in China, often consisting of about 60 students, are too large for teachers to manage effectively. Faced with a large number of students with different speaking levels, teachers are unable to tailor to the needs of each individual and personalized learning becomes impossible. Speaking is very challenging for Chinese students and requires a lot of hard work. However, students seldom have chances to speak in class and are not motivated to practice after class. Without enough practice and output, speaking ability is hard to be improved.

Speaking skill plays a fundamental role in language skills. With the advance of college English teaching reform, although the current oral English teaching has made great progress, the existing problems cannot be ignored. English teachers should actively explore new teaching models to deal with these problems, and promote greater development of oral English teaching.

\section{Advantages of Mahara E-Portfolio Platform}

To solve above-mentioned problems, this paper proposes a college oral English teaching model based on Mahara, which is an open source electronic folder, including e-Portfolio, web blog, resume and learning communities. It is designed to provide users with lifelong learning, reflective learning and personalized learning. User-friendly and free of charge, Mahara is a suitable tool for oral English teaching. Maraha e-portfolio has the following advantages:

Developing Autonomous Learning Ability. E-Portfolio could be used to facilitate and enhance students' self-regulated learning experiences. It enables students to form their own learning styles 
and develop autonomous learning ability. Through Mahara, everyone can design learning plans and share learning resources to achieve the requirements of personalized learning. Students are guided and inspired to find out their unique strong points, then develop skills of learning, critical thinking and being creative.

Changing Learning and Teaching Approach. Nowadays the learning and teaching approach has shifted from teacher-centered to student-centered. From this perspective, the teacher and the student have exchanged places. Instead of being a dominator, the teacher is regarded as a mediator and facilitator who participates and cooperates with students. On the other hand, students are encouraged to get involved and their roles shift from passive receivers to active constructors of knowledge.IT evolution has played an important role in the change, as it has favored new methodological tools that give students greater autonomy during learning experience. Specifically, e-Portfolio seem to fit in well with the perception of learning process and help construct students' knowledge. Through Mahara, students upload artifacts, showcase learning process and write reflection reports. Teachers assess students' learning outcome through e-Portfolios and give feedbacks to students. In this process, students are responsible for their own study by cooperating and gaining support from teachers and peers,

Enhancing Cooperative Learning. E-Portfolio helps students develop teamwork spirits, speaking ability and reflective competence. Additionally, it can effectively promote interactive learning, strengthen exchanges and communication between students and study partners, so as to help students better accomplish learning objectives and construct knowledge. By cooperating than competing, students reduce learning anxiety and enhance motivation. Meanwhile, students can see clearly about their strengths and weaknesses after uploading artifacts and being assessed by teachers and peers. Through record of e-Portfolio, students have a clear vision about their learning process and progress. Finally, by writing reflection report, students realize how to improve artifacts and better tap their potentials.

\section{Challenges and Solutions}

Educational e-Portfolio is one of the electronic tools that can be used during learning and teaching. It motivates students to learn and become independent learners. The incorporation of e-Portfolio into teaching has been successful in many countries and regions over the years. Nonetheless, there are still some difficulties in the process of using e-Portfolio platform. The following are major challenges and possible solutions.

Motivating Students to Produce High-Quality E-Portfolios. Students' motivation is a key prerequisite for effective learning from e-Portfolios. If students are not highly motivated, they may see e-Portfolio work as a burden and merely do the minimum work required to get reasonable grades, resulting in inefficiency of using e-Portfolio. In order to motivate students to make full use of e-Portfolios, we should design tasks which they find interesting. We can integrate social networking software such as QQ and Wechat into E-portfolio planform so that students can share their works with friends. Furthermore, a mechanism can be built to give students external rewards, such as holding best e-Portfolio contest.

Familiarizing Students and Teachers with E-Portfolio Platform. Teachers and students may experience extensive difficulties in using Mahara platform for the first time. Also, in the process of uploading works and resources, many technical problems may occur unexpectedly. To tackle the problems, a detailed user manual should be prepared in advance and a technical support team is recommended to be established.

Balancing Workloads Imposed on Teachers. Teachers are required to upload learning materials, check and assess each student's works and reflection reports. Some teachers regard e-Portfolio as an additional burden on their already heavy workload, and some express the concern that it is too time-consuming to monitor students' progress. Besides, teachers have to learn technical skills 
related to Mahara e-Portfolio platform, which is no easy job for some teachers. Still, teachers dread that unexpected technical problems might appear while they are doing demonstrations in class, resulting in embarrassment. In attempting to relieve teachers' burden, universities can hire students as teaching assistants to help teachers.

\section{Conclusion}

E-portfolio, as an electronic tool, is widely used at universities in many countries and regions in the world. Along with the diffusion of technology in education, Chinese educators and scholars has shown concern about it and has done related research. However, it is far from enough both in theory and in practice. By incorporating e-Portfolio into English speaking course, teachers can achieve the objectives of oral English teaching reform and cater to the needs of students with different learning styles. It also facilitates and enhances learners' self-regulated learning experiences. However, there are some problems and challenges in the process of using Mahara e-Portfolio platform. The dissemination of e-Portfolio requires cooperation among universities, teachers and students: universities should speed up information technology and improve teaching conditions; teachers should change traditional "teacher-centered" teaching concept and encourage students to learn autonomously and independently; students should realize the benefits of using ePortfolios, and cooperate actively with teachers.

\section{References}

[1] Cole, D. J., Ryan, C. W., Kick, F., \& Mathies, B. K. (2000). Portfolios across the curriculum and beyond (2nd ed.). Thousand Oaks, C. A.: Corwin Press.

[2] Nelson, J. L., Palonsky, S., \& McCarthy, M. R. (2010). Critical issues in education: Dialogues and dialects. Boston, MA: McGraw Hill.

[3] Butler, P. (2006). A Review of the literature on portfolios and electronic portfolios (pp. 1-23). New Zealand: Massey University College of Education.

[4] Barrett, H. (2000). Create your own electronic portfolio. Learning and Leading With Technology, 27(7), 14-21.

[5] Abrami, P. C., \& Barrett, H. (2005). Directions for research and development on electronic portfolios. Canadian Journal of Learning and Technology, 31(3), 1-15. 